\title{
Überzeugt in mehreren Studien
}

Drei unterschiedliche Studien untersuchten die Eigenschaften von iBOND Universal, dem neuesten Adhäsiv von Heraeus Kulzer. Eine Studie der Universität Erlangen zu Silikat-Keramiken attestierte iBOND Universal dank der Verwendung eines Ceramic Primers die stärkste Haftung unter den getesteten Adhäsiven (Zorzin J et al. Poster presentation \#P62 at the 23th European Dental Material Conference in Nuremberg, Germany, 27-28 August 2015). Eine Untersuchung der Universität Mainz wiederum bestätigte die geringe Techniksensibilität von iBOND Universal: Es zeigt eine Haftfestigkeit auf Goldstandard-Ebene (Ehlers V et al. J Dent Res 2015;

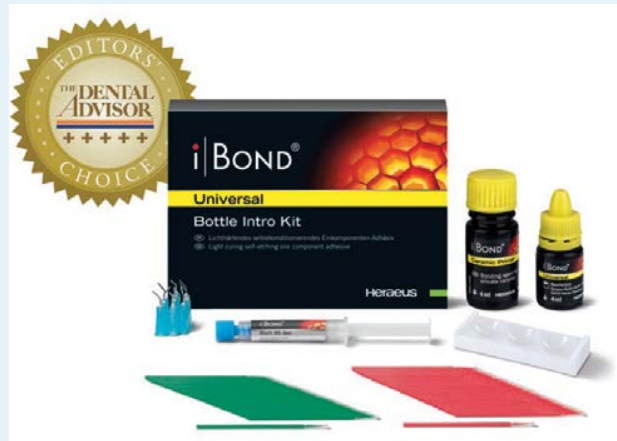

94: 0544 CED). Darüber hinaus bescheinigte die Universität Marburg iBOND Universal in einer Studie eine gute Randadaption (Frankenberger R et al. Unpublished data. Data on file). Insgesamt attestierten die 3 Studien iBOND Universal eine vielseitige und zuverlässige Anwendbarkeit.

Nach einer Pressemitteilung der Heraeus Kulzer GmbH, Hanau 